The Joumal of Phlosophy (1978), pp. 5-27. Sobre esta perspectiva se puede consultar el comentario de G. Currie: «Works of Fiction and Nlocutionary Acts, Philosophy and Literature, 2 (1986). pp. 304-307; $M$. Nussbaum, Love's Knouledge, Nueva York, Oxford University Press, 1990, pp. 5-8.

11. M. Weber. *Excurso. Teora de los estadios y direcciones del rechazo religioso del mundo*. en Ensayos sobre Sociologfa de la Religión, Madrid, Taurus, 1983, vol. I, pp. 437-466. Sobre la diferenciación de esferas, J.M. Ferry, «Fait, Sens, Validité dans l'architectonique des sciences contemporaines*, Revtle de Metaphisique et Morale, $93(1988)$, pp. 105-125.
12. Asf lo plantean S. Darwall, A, Gibbard y $P$. Railton, *Toward "Fin de siècle" Ethics: Some Trends*, The Philosophical Review, 101 (1992).

13. Como to denomina J. Nancy, en J.F. Courtine y M. Deguy, Du sublime, Berlin, 1988, pp. 7-9.

14. R. Barthes, Critique et vérite, Paris, Seuil, 1966, pp. 37.40; Essais critiques, Paris, Seuil, 1964, pp. 13-14, 139-142, 221-237.

15. En los términos de M. Walser, «Alpen-Laokoon oder Uber die Grenze zwischen Literatur und Gebirgex, en Wor ist ein Schrifsteller?. Francfort, Suhrkamp, 1979, p. 60 .

16. M. Foucault, Histoire de la sexwalité L'usa. ge des plaisim, Paris, Gallimard, 1984, pp. 15-19.

\title{
Composición: Adorno y el lenguaje de la filosofía
}

\author{
GERARD VILAR \\ Universidad Autónoma de Barcelona
}

Analog [zur Musik] hâtte Philosophie nicht sich auf Kategorien zu bringen sondern in gewissem Sinn erst $x t$ komponieren.

$$
\text { Negative Dialektik, p. } 44
$$

Al contrario de lo que ha ocurrido con otros de los nombres que se asocian a la primera generación de la Escuela de Francfort, el de T.W. Adorno no ha dejado de crecer en estatura filosófica desde quc hace ahora veinticinco años falleciera durante sus vacaciones estivales en Suiza. Ello es con seguridad indice de que una parte sustantiva de las reflexiones encerradas en su obra conectan con problemas medulares de la filosofía contemporánea. Uno de ellos es sin lugar a dudas el que, en multitud de variaciones, reproduce la clásica cuestion de a qué género discursivo pertenece la filosofia, o de la relación existente o las relaciones posibles en ella entre la lógica y la retórica. Desde modernas posiciones desconstruccionistas, postestructuralistas o neo- pragmatistas se defienden planteamientos que implican una amuerte retórican de la filosofía en la estela del gesto anticipado ya por Nietzsche $y$ cuyo más inmediato precedente encontramos en el último Heidegger. Dicha muerte retorica de la filosofia y su zozobra en la literatura se produce como consecuencia del abandono por «metafísicas de la pretensión de verdad y racionalidad que ha acompañado al pensamiento filosófico desde la antigüedad. Derrida, Deleuze o Rorty ya no distinguen entre Hegel y Mallarmé o entre Proust y Wittgenstein más que por la fuerza literariamente iluminadora y retóricamente reveladora y patentizadora que poseen sus textos. $O$, al menos, eso es lo que se sostiene acerca de la posición de dichos pensadores desde los planteamientos situados al otro extremo del espectro como los de Habermas, Putnam o Apel. En mi opinión, y sin perjuicio de las evidentes diferencias de presupuestos de unos y 
otros, en el punto medio de ese espectro cabria situar a Adorno.

\section{La irrupción de lo irreductible}

Adomo formulo muy tempranamente buena parte de sus principales intuiciones filosóficas, entre ellas la de que la derrota de la Razón condenaba a la filosofía a buscar formas inusuales de comunicación que se hicieran cargo de la irreductibilidad de lo real, formas entre las que destacaba singularmente el ensayo estético. Ello pudo comprobarse cuando se publicaron en 1973 los escritos filosóficos juveniles de Adorno, entre los que hay que mencionar, por lo que a nuestro tema se refiere, "Die Aktualität der Philosophien,' Antrittsrede o lección inaugural de Adorno como Privatdozent en la Universidad de Francfort en 1931, así como las «Thesen uber die Sprache der Philosophen", escritas tambien a principios de los años treinta. ${ }^{2}$ Leído por Adorno ante Horkheimer, Mannheim, Wertheimer y otros, a quienes por cierto mas bien disgust $6{ }^{3}$ el primero de los textos mencionados presentaba un programa teologico materialista general en el espiritu de Benjamin y Kracauer. De la constatación de la crisis de la pretensión filosófica a la totalidad, la pérdida de autonomía a la que se ve abocada la filosofía al dejar de creer en una realidad fundada en la ratio y encontrarse con el quebrantamiento de la legislación racional autónoma por parte de un ser que no se le adecua ni puede ser objeto, como totalidad, de un proyecto racional, Adorno no extraía la consecuencia de un inevitable abandono de todas las pretensiones racionales de la filosofía. Esta no estaría por encima ni por debajo de la ciencia, sino que se distinguiria por su naturaleza como actividad interpretadora. "Las ciencias particulares acep- tan sus hallazgos [...] como algo ulteriormente insoluble que descansa sobre si mismo, en tanto la filosofía concibe ya el primer hallazgo con el que se tropieza como un signo que está obligada a descifrar», lo cual lleva a la gran paradoja de que «la filosofia ha de proceder a interpretar una y otra vez, y siempre con pretensión de verdad, sin poseer nunca una clave cierta de interpretacionn.4 Su idea de interpretación, sin embargo, no tenía que ver con un concepto platónico de sentido, como algo ya dado o presente que habría que investigar y descubrir. Fiel a algunas ideas benjaminianas, de lo que se trataría es de iluminar como un relámpago la figura del enigma y hacerla así emerger. "La auténtica interpretación filosofica no acierta a dar con un sentido que se encontraría ya listo y persistiria tras la pregunta, sino que la ilumina repentina $e$ instantáneamente, y al mismo tiempo la hace consumirse» (p. 89). Como medio para «interpretar una realidad carente de intención", Adorno proponía la construcción de constelaciones cambiantes, de sordenaciones tentativas hasta que encajen en una figura legible como respuesta mientras la pregunta se esfuma" (ibid.). En lugar, pues, de la referencia a la totalidad -el todo es lo no verdadero, gustaría decir Adorno años más tarde- el nuevo presupuesto fundamental de la filosofía había de ser el de descomponer esa totalidad. Ello implicaba otro modo de pensar que ya no podía referir lo particular a lo universal, antes bien la filosofía quedaba privada de cualquier patrón de medida constante para conferirle a la facticidad histórica el poder que les correspondra a las invariantes, haciendo que éstas se esfurmasen en un ajuego estético de imágenes" que "transformaría la prima philosophia en ensayismo filosofico". "Una filosofía así -escribia 
Adorno desafiando el neokantismo de fondo de sus interlocutores de entonces- no recorrerá hasta el final el camino de los supuestos racionales, sino que se quedará plantada allı donde le salga al paso la irreductible realidad... La irrupción de lo irreductible sin embargo se lleva a cabo de una forma histórica concreta, y por eso se le da el alto al movimiento del pensamiento hacia las suposiciones. La productividad del pensamiento sólo es capaz de acreditarse dialécticamente en la concreción hîstórica. Ambas establecen comunicación en los modelos. En cuanto a los esfuerzos por buscar una forma adecuada para esa comunicación, con mucho gusto cargo a mi cuenta ese reproche de "ensayismo" " (pp. 101 y s.).

\section{El lenguaje desmoronado y la comunicación}

El ensayismo por el que Adorno tan tempranamente se pronunció no era, por consiguiente, producto de una elección de estilo expresivo entre otras posibles, sino una necesidad resultante del modo en que comprendía la situación misma de la filosofía contemporánea. Que en filosofía el modo de expresión no es indiferente al pensamiento es una convicción que Adorno compartió desde el principio con sus mentores Hegel y Benjamin. Hasta qué punto era ello así se puede colegir en el otro texto antes mencionado. Las "Tesis sobre el lenguaje de los filósofos» demuestran en qué medida su autor era consciente de que el medio del pensamiento filosófico es el medio de su expresión, esto es, el lenguaje mismo. En ellas Adorno rechazaba la distinción entre forma y contenido del lenguaje filosófico como una variante de la distinción idealista entre forma y contenido del conocimiento, un producto cosificado de la consciencia idealista que entiende el lenguaje según el modelo del nombre designador. Pero el lenguaje filosófico, que apunta a la verdad, no conoce signos. En él las palabras no son signos, sino el lugar en el que historia y verdad irrumpen. La inseparabilidad historica de lenguaje y objeto, que no hay tampoco que interpretar como identidad de los mismos, supone que no hay varias maneras de presentar adecuadamente un mismo objeto. De ahi que la exigencia de que el lenguaje filosófico sea claro y comprensible en aras de la comunicabilidad social forma parte de la misma consciencia cosificada. En una sociedad homogénea no sería preciso exigir comprensibilidad. La adecuación del lenguaje al objeto es producto de una sociedad atomizada y desmoronada en la que la comunicación no es otra cosa que una forma de falsedad y engaño.

Adorno, como es bien sabido, se distinguió siempre por una radical desconfianza frente a toda forma de comunicación usual. «La comunicación - escribiria contundentemente en la Teoría estética - no es sino la adaptación del espíritu a lo útil, no es sino el situarse a sí mismo entre las mercancías, y lo que hoy se llama sentido participa en esta monstruosidad. $x^{5}$ En uno de sus últimos escritos, "Sujeto y objeton, recogido en Consignas, acaso sea donde mejor expuso las razones de esa desconfianza: "el concepto actual de comunicación es tan denigrante porque traiciona lo mejor, el potencial de un acuerdo de hombres y cosas, para entregarlo al intercambio entre sujetos según los requerimientos de la razón subjetivan. ${ }^{6}$ La auténtica comunicación es la que se darfa en una sociedad pacificada, en la que la dominación de la naturaleza y de los hombres hubiese sido substituida por la reconciliación entendida ésta no como la indiferen- 
ciada unidad de sujeto y objeto, sino como la comunicación de lo diferente, un estado, pues, de diferenciación sin sojuzgamiento en el que lo diferente es compartido (ibid.). Entre tanto no llegue la paz, toda exigencia de comunicabilidad es reaccionaria. Adorno llegó a extremos casi heideggerianos en su rechazo de la comprensibilidad: en $\mathrm{Mi}$ nima moratia incluso escribiría aquello de que "sólo son verdaderos los pensamientos que no se comprenden a si mismosn (p. 192).

A una sociedad atomizada y desmoronada le corresponde un equivalente estado del lenguaje. Con ello Adorno recoge el conocido topos de la crisis del lenguaje y la fragmentación del sentido que informa toda la cultura centroeuropea del primer tercio del siglo XX. «El filósofo-dice la más conocida de las tesis que comentamos-, se halla hoy ante el lenguaje desmoronado. Su material son las ruinas de las palabras que le unen a la historia. No nos está permitido pensar una palabra como ya dada; pero tampoco inventarla» (pp. 368 y s.). El filosofo no puede, pues, ni confiar en la capacidad comunicativa de un lenguaje en ruinas, ni tampoco puede prescindir del viejo lenguaje e inventar uno nuevo como pretendiera Heidegger contra cuya huida de la historia dirige Adorno sus críticas. El tercer y único camino que le resta al filosofo es el de configurar las palabras de modo que surja la nueva verdad. El lenguaje configurativo (p. 369), que traduce a términos lingüisticos la idea benjaminiana de constelación asumida por Adorno, supone que la filosofía aes hoy posible como crítica del lenguajen (p. 369), pero como «crítica estética». Pues el único criterio que resta de la preservación configurativa de la fuerza historica del lenguaje está en "la dignidad estética de las palabrası (p. 370). Con este alzaprimado de la función estética del lenguaje, alzaprimado que se corresponde con el que Benjamin hacía de lo que llamaba la dimensión mágica o mimética del mismo, Adorno reafirmaba como su amigo y maestro la «significación constitutiva de la crítica estética para el conocimiento" (p. 370), lo cual implicaba, más aún, «la creciente significación de la crítica filosófica del lenguaje como inicio de la convergencia entre arte y conocimienton (p. 370). Esta relación entre arte y filosofía, entre la armonía estética y la verdad, sólo puede comprenderse, sostiene Adorno, dialécticamente. La despedida de la totalidad implica la despedida de la unidad inmediata de lenguaje discursivo y verdad. Ahora el lenguaje no discursivo del arte posee un "carácter cognitivo" no metafísico (ibid.) y queda conectado con la verdad en no menor medida que la teoria misma.

¿Procede Adorno con este resultado a realizar una forma de estetización de la teoria, como tantas veces se ha afirmado? Bueno, Minima moralia es una obra de la que no parece infundado decir algo asi, pero la Filosofía de la nueva música, la Dialéctica de la Ilustración, la Dialéctica negativa o la misma Teorta estética, por no citar otras obras menores no parece que se dejen predicar con esta fórmula con tanta facilidad. Veamos, pues, en unas pocas y muy limitadas calas cómo desarrolló Adorno en momentos posteriores de su vida como filósofo y crítico literario y musical estas ideas de juventud.

\section{Moral y estito}

Acabamos de recordar el lugar común que dice que Minima moralia es la obra en la que Adorno más se aproximó a su ideal de Filosofía como teoría estetizada contraria a toda pretensión de totalidad y sistema. ${ }^{7}$ No me consta, 
sin embargo, que nadie haya dudado seriamente alguna vez de que se trata de una auténtica obra teórica, de un libro de filosofia que, aunque tiene una fuerte dimensión literaria, no es literatura. Aunque se trata de una obra escrita, según su autor, desde el punto de vista de la experiencia subjetiva, a pesar de que la invocación de Nietzsche en ella es más que explrcita, y de su carácter fragmentario y aparentemente sin contextura teórica, Minima moralia no está en absoluto exenta de la forma conceptual rigurosa que suele caracterizar todos los escritos de Adorno. Por lo pronto el libro como totalidad formal cumple con aquello que se propone como norma en el último de sus fragmentos y que es una clara reivindicación de la filosofía contra cualquier tentación de abandonar la explicita declaración del punto medular del programa filosófico adorniano: "el único modo que le queda aún a la filosofía de responsabilizarse a la vista de la desesperación es intentar ver las cosas tal como aparecen desde la perspectiva de la redención. El conocimiento no tiene otra luz iluminadora del mundo que la que arroja la idea de redención: todo lo demás se agota en reconstrucciones y se reduce a mera técnica. Es preciso fijar perspectivas en las que el mundo aparezca trastocado, enajenado, mostrando sus grietas y desgarros, menesteroso y deforme en el grado en que aparece bajo la luz mesianica. Situarse en tales perspectivas sin arbitrariedad ni violencia, desde el contacto con los objetos sólo le es dado al pensamienton. ${ }^{8}$ Adorno atribura, así, a la filosofía una tarea moral: una «responsabilidad" a la vista de la desesperación. Esa es la idea seminal de la teoria critica: un conocimiento con moral. De ahí que la cuestión del modo de expresión en filosofía sea también una cuestión normativa. Uno de los frag- mentos de Minima moralia se titula precisamente "Moral y estilo". En él vuelve sobre este tema constante en su obra desde su juventud, como hemos visto anteriormente, que es la inteligibilidad del discurso filosófico. Adorno reflexiona acerca de la relación de proporcionalidad inversa existente entre la precisión, el esmero y la adecuación de la expresión filosófica, de un lado, y la comprensibilidad o inteligibilidad, por otro. La filosofía no puede nadar con la corriente de nuestra época que exige la sencillez y claridad comunicativa, la logica del esquematismo alienante, de la palabra acuñada por el comercio. Eso sería una perversión que lleva a la pura "desmoralización» de la tarea filosófica. Por el contrario, hay que "ver en todo consejo de atender sobre todo a la comunicación una traición a lo comunicadon (p. 100) y permanecer fiel a la logica del trabajo del concepto y del esfuerzo y la paciencia que éste exige.

\section{El ensayo y la felicidad traicionada}

Desde mediados de los años cincuenta Adorno volvió a enfrentarse con los problemas del lenguaje de la filosofía, pero esta vez sistemáticamente, demorándose en ellos de una manera hasta entonces insólita. A esta tarea se dedicó especialmente en el célebre artículo $\mathrm{El}$ ensayo como forman, un extenso texto escrito entre 1954 y 1957 y que abria el primer volumen de las Notas de literatura aparecidas ese último año y luego, diez años más tarde, nuevamente en su obra cumbre, la Dialectica negativa. En el primero de estos escritos - convertido con el tiempo como ocurriera con el escrito de Lukács en un clásico imprescindible sobre el género-, Adorno reivindica el ensayo frente a la ortodoxia $y$ la voluntad metódica y sistemática como la forma de exposición más ade- 
cuada para un pensamiento crítico radical. «El ensayo da cuenta a la consciencia de lo no idéntico, aun sin expresarlo siquiera; es radical en el no radicalismo, en la abstención de reducirlo todo a un principio, en la acentuación de lo parcial frente a lo total, en su carácter fragmentario. ${ }^{y}$ El ensayo se yergue contra el platonismo de la tradición filosófica occidental que sostiene la indignidad de lo perecedero, lo parcial y lo fragmentario frente a lo eterno, la totalidad y lo verdadero. Por ello wel ensayo no se propone buscar lo eterno en lo perecedero y destilarlo de ello, sino más bien eternizar lo perecedero... En el enfático ensayo el pensamiento se libera de la idea tradicional de verdad... busca los contenidos de verdad como históricos en sí mismos" (p. 21). El ensayo se presenta, desde el punto de vista de la articulación conceptual, no como un continuo operativo, lineal, «sino que los momentos se entretejen como los hilos de una tapicerías (p. 23), como configuraciones de conceptos que se reinen en un todo legible en el que los elementos discretos están separados y contrapuestos. Así el ensayo no es "andamiaje ni construcción", sino que, como configuraciones, los elementos cristalizan por su movimiento. "La configuración es un campo de fuerzas, como en general, bajo la mirada del ensayo, toda formación espiritual tiene que convertirse en un campo de fuerzas" (p. 24). Un punto fundamental de la defensa adorniana de las configuraciones frente al análisis deductivo es que aquellas son más fieles a la realidad misma: «El ensayo piensa discontínuamente, como la realidad es discontinua, y encuentra su unidad a través de las rupturas, no intentando taparlas. La armonía del orden logico engaña acerca del ser antagonistico de aquello a que se ha impuesto ese orden" (p. 27).
Y bien, se preguntarán muchos, $¿$ pero no es esto precisamente lo que encontramos en el arte, y singularmente en el arte moderno, este tipo de sintesis estética inorgánica? Adorno incluso vincula el ensayo a una cierta idea de felicidad, lo que recuerda a la promesse de bonheur del arte: al reconocer el parentesco del ensayo con la retórica, afirma el origen de ésta en la adaptación del pensamiento a la comunicación, a la satisfacción de los oyentes. El ensayo conserva restos de aquel elemento comunicativo de que carece la comunicación cientifica. Así pues, «la satisfacción que la retórica quiere suministrar al oyente se sublima en el ensayo hasta hacerse idea de la felicidad frente al objeto... Al reflejar como sin violencia el objeto, el ensayo se queja calladamente de que la verdad traicionara a la felicidad y, con ello, a si misma» (pp. 33 y s.). Pero esa promesa de felicidad se nos hace en el ensayo filosófico, como en el arte moderno, a través de la negatividad, esto es, negandonos el placer, el sentido común, la buena consciencia y el orden del mundo cotidiano: "Para la felicidad, que era sagrada para Nietzsche, el ensayo no conoce más nombre que el negativo... Por eso la más íntima ley formal del ensayo es la herejía. Por violencia contra la ortodoxia del pensamiento se hace visible en la cosa aquello, mantener oculto lo cual es secreto y objetivo fin de la ortodoxia” (p. 36).

Por consiguiente, y resumiendo, es cierto que en Adorno arte y filosolía tienen algo en común: "La consciencia de la no identidad de exposición y cosa impone a la exposición un esfuerzo ilimitado.

"Esto y sólo esto es lo que en el ensayo resulta parecido al arte" (p. 29). Recientemente ha habido algún intento de repensar la estética adorniana desde la teorfa de lo sublime de Kant 
como kexposición negativa» o "presentación de lo que no se puede presentar. ${ }^{10}$ Estos intentos son del todo razonables, pero deberían complementarse con una teoría de la filosofía análoga a aquella.

\section{Terminologia filosofica y obscuridad}

Ahora, sin embargo, hay que subrayar la continuidad del pensamiento de Adorno en todos los aspectos fundamentales que aparecen en aquellos dos textos del joven Adorno que se han comentado al principio. Para convencerse plenamente de ello basta acudir a las lecciones de introducción a la filosofia impartidas en 1962 y 1963 con el título Terminología filosófica y aparecidas póstumamente diez años más tarde con el mismo título. La justificación del título aclara un punto básico del programa filos6fico adorniano: «A la filosofía le es esencial su lenguaje. Los problemas filosoficos son ampliamente problemas del lenguaje filosóficon." Ello constituye la principal diferencia entre ciencia y filosofía, lo que hace que la filosofía no sea meramente referible. La filosofía no tiene su objeto, sino que lo busca, quiere expresar con conceptos algo que no es propiamente conceptual (p. 63). Puesto que los objetos no se dan en general de manera inmediata al lenguaje filosófico, como ocurre en las ciencias positivas, está forzado dicho lenguaje a decir lo que enuncia de modo exagerado o metafórico (p. 52). Por ello esta esencia metafórica o trópica es casi inalienable. Si se extirpase totalmente tal elemento objetado y no se emplease en la filosofía ninguna palabra que dijese más de lo que debe decirse ahora y sólo en este lugar, entonces sería imposible formular pensamientos filosóficos de ninguna clase (p. 53). Pero ello no implica una equiparación de arte y filoso- fía: «Frente al arte, la filosofía representa lo no conceptual siempre y sólo por medio del concepto, o bien representa lo que no puede pensarse mediante el pensamiento [...] alcanzar [...] con el lenguaje lo no decible mediante el lenguaje [...] la filosofia [...] es el tercero o el otro frente a la ciencia y frente al arte» (p. 67).

En "Skoteinos", un texto de la misma época dedicado a la "oscuridad" de Hegel, criticando por enésima vez a quienes exigen claridad y simplicidad a la filosofia, afirma Adorno que en el lenguaje las funciones de expresion y de comunicación están estrechamente entretejidas. Aun cuando en la filosofia el momento expresivo (o metafórico, o estético, o mimético) sea el momento esencial, éste no es simplemente independiente de la comunicación, "ya que de otro modo escaparía a toda crítica enderezada a sus relaciones con la cosa, y se degradaría a pretensión arbitrariam." Lo conceptual y lo mimético. la experiencia filosófica y el relampagueo de la constelación se pertenecen mutuamente: "La experiencia filosofica no puede prescindir, en el horizonte de la vaguedad más indeleble, de la evidencia ejemplar, del "esto es asi"; tampoco ha de quedarse parada en tal punto, pero a quien, en definitiva, no se le encienda súbitamente semejante evidencia en la lectura de algunos grávidos pasajes de la Logica de Hegel, quien no advierta con lo que ha acertado (aunque sea de manera no perfectamente articulada), comprenderá tan poco como el que se extasíe ante lo meramente aproximado del sentimiento filosófico. Los fanáticos de la claridad querrían extinguir aquel súbito relampagueo" (pp. 142 y s.).

Agotemos ahora la exposición de lo que Adorno nos dejo escrito acerca de la naturaleza del lenguaje filosofico. Un aspecto fundamental de este en su 
semejanza y diferencia con el arte es el que tiene como centro la música que, como es sabido, para Adorno, fue siempre el laboratorio del que extrajo su concepto más puro de arte. ${ }^{13}$ La analogía entre la filosofia y la música tiene que ver con la composición.

\section{La teoria como composición}

La filosofía se propone una utopia: pensar lo no idéntico, lo que significa comunicar lo incomunicable, penetrar con conceptos lo que no es conceptual. Esta utopía convierte en aporética la tarea de la filosofía. Puesto que "pensar quiere decir identificar", ${ }^{14}$ la filosofía es una tarea imposible. Sin embargo Adorno defendía la necesidad y el sentido de esta tarea: “A la filosofía le es imprescindible [...] confiar en que el concepto puede superar al concepto, al instrumento que es su límite; esta confianza en poder alcanzar lo supraconceptual es asi una parte necesaria de la ingenuidad de que adolece. De otro modo tendria que capitular, y con ella todo lo que fuera espiritu. Sería imposible pensar hasta la operación más sencilla, no existiría la verdad, en rigor todo sería nada. Sin embargo, [...] no dispone de otro escenario que lo que él mismo oprime, desprecia y rechaza, La utopía del conocimiento sería penetrar con conceptos lo que no es conceptual sin acomodar esto a aquellos» (DN, p. 18). La analogía de fondo con la música salta para Adorno inmediatamente: "La expresión de lo que a ella misma le resulta inexpresable. Este es el punto en que realmente coincide con la música" (DN, p. 113). Pero ¿cómo concretar esta vaporosa "coincidencia" entre música y filosofia?

Adorno intentó hacer plausible esa tarea aporética acercando la reflexión filosófica a la composición musical. La constelación, la configuración, la para- taxis están en realidad pensadas desde la experiencia del lenguaje musical. «La filosofía - escribe en un pasaje decisivo de la Dialectica negativa-, en vez de reducirse a categorías, tendría en cierto modo que comenzar componiêndose» (DN, p. 41) y, en otro lugar, la escritura filosófica hasta se le aparece a veces como "la concatenación asociativa de las frases a modo de un rondon. 15

La filosofia se ha desinteresado casi siempre de la exploración de los objetos a través de sus constelaciones. Por eso a Adorno le parecen modélicas las tentativas de las ciencias sociales no positivistas como es el caso de la sociología de Max. Weber, quien defiende que los conceptos sociológicos deben ser compuestos poco a poco a partir de los elementos singulares perceptibles en la realidad historica. Sobre ello Adomo comenta lo siguiente: ucon la composición de que habla Weber pudiera pasar algo parecido a lo que le ocurre a su análogo, las composiciones musicales. A pesar de producirse subjetivamente, sólo están logradas si la producción subjetiva desaparece en ellas. El contexto -la constelacion-creado por la producción subjetiva se hace legible como signo de la objetividad".16

\section{Vétigo y retorica}

Que la filosofía deba componerse, en lugar de desplegarse en línea recta y de reducirse a categorías, es una servidumbre en la que "la filosofía confiesa su esencia lingüística» (DN, p. 61). Pero en ella se reconoce tambien su grandeza, que es la de la abertura de lo que siempre tiene que ser pensado de nuevo y, claro es, la abertura a lo inédito, que lo es sólo en relación a lo familiar. $Y$ esa es la grandeza de la retórica. "La retorica representa en la fi- 
Josofia lo que no puede ser pensado de otro modo que en el lenguaje. Impone su presencia en los postulados expositivos, que distinguen la filosofía de la comunicación de contenidos conocidos y fijados de antemanom (DN, p. 61). Pero esta indisolubilidad del momento retórico y el momento lógico en la filosofía implica no sólo el esfuerzo $y$ el rigor extremos de la palabra, sino también el vértigo de lo abierto y de la negatividad de la experiencia filosófica. "Todo conocimiento fructífero -escribe Adorno con pregnancia-, tiene que echarse a fondo perdido en los objetos. El vértigo que da es Index veri; el shock de lo abierto es la negatividad, su revelación necesaria dentro de lo seguro y lo siempre igual, falsa sólo para lo que es falso" (DN, p. 40).

Adorno nos legó una de las formulaciones más pregnantes del ethos filosófico socrático realizadas en este siglo. Esta formulación implica la reivindicación de lo que se podría llamar sin exceso una retórica negativa. Dicha negatividad es casi en todos los aspectos común a la filosofía y al arte. Para
Adorno, y en eso creo que estaba totalmente en lo cierto, toda filosofía que no es literatura está muerta, pero toda filosofía que es sólo literatura está vacfa. La dialéctica del concepto y su exposición la pensó en términos demasiado "expresionistas", términos tras los cuales encontramos una filosofía de la reconciliación. La retórica negativa es sin duda un medio expresivo de la filosofia totalmente legítimo, pero no lo son menos las formas de análisis conceptual o de comentario textual siempre y cuando se acompañen de la imprescindible consciencia falible. Los paralelismos entre el arte y la filosofia se mantienen cuando abandonamos la teología negativa adorniana, sólo que ahora ya no podremos postular con tanta claridad como él hiciera lo que es progreso y lo que es reacción: así como Strawinsky se nos presenta como otra tradición legítima frente a Schonberg, también el pluralismo se instala en la filosofía. La pluralidad de los géneros filosóficos no puede sino ser paralela de la pluralidad de movimientos artísticos.
1. Gesammette Schriftan, Francfort, Suhrkamp, 1973, vol, 1. pp. 325-344. Existe version castellana con el título Actzalidad de la filosofa, Barcelona, Paidós, 1991, pp. 73-102.

2. Ibident, pp. 366-371. No conozco traducción castellana de estas tesis.

3. Cfr. R. Wiggershaus, Die Fratkfurter Schule, Munich, DTV, 1986, pp. 111 y s.; J. Frichtl y Calloni (eds.), Geist gegen den Zeirgeist. Erimem an Adonto, Franctort, Subrkamp, 1991, p. 15.

4. Versión castellana cỉ., p. 87.

5. Teoria estésica, Madrid, Taurus, 1971, p. 102.

6. Consignas, Buenos Aires, Amonortu, 1971. p. 145. Véase también Dinléctica negativa, Madrid, Taurus, 1975, p. 346.

7. Cfr, pot ejemplo. A. Wellmer; sobre la dialéctica de modentidad y postntodentidad. La critica de la razón después de Adonto, Madrid, Visor, 1993, pp. 137 y s.
8. Mininta Moralia, Madrid, Taurus, $1987, \mathrm{p}$ 250.

9. Notas de Literatura, Barcelona, Ariel, 1962. p. 19.

10. A. Wellmer, Endspicle: Die unversöhultche Moderne, Francfort, Suhrkamp, 1993, pp. 178 ss. También W. Welsch, Asthetisches Denken, Stuttgart, Reclam, 1991, cap. 1.

11. Terminología fitosofica, Madrid, Taumus, 1976, p. 7 .

12. Tres estudios sobre Hegel, Madrid, Tatmus, 1969, p. 139.

13. Minima moralia, ed. cit, p. 224; Teoria esterica, ed. cit., p. 297.

14. Dialectica negativa, ed. cit., p. 13. (A partit de ahora, abreviado DN).

15. «Parataxis*, en Noter zur Literatur, Francfort, Suhrkamp, 1974, p. 472 .

16. Dialectica negativa, ed. cit., p. 168. 